\title{
MR rectum imaging with ultra sound gel as instrumental contrast media in tubulovillous adenoma
}

\author{
Amela Sofić, Nedžad Šehović, Šerif Bešlić, Besim Prnjavorac, \\ Nurija Bilalović, Jasmin Čaluk, Damir Sofić
}

Institute of Radiology, Clinical Center of University of Sarajevo, Sarajevo, Bosnia and Herzegovina

\begin{abstract}
Bacground. Colorectal polyps are frequent and can be found in $10 \%$ of adults, most common in elderly with prevalence of $20 \%$ in age group of 60 . Over $90 \%$ cases of cancer are being developed from benign adenomas. Colorectal cancer (CRC) is a significantly large cause of death right after bronchial cancer in males, and breast cancer in women. Therefore, a standpoint was adopted that the removal of polyps as precursor will prevent the development of colorectal area cancer. Polyps can occur as peduncular or sessile. Adenomas are grouped in three subtypes based on histological criteria: tubular, tubulovillous and villous. Villous adenomas are larger than others and show a higher level of dysplasia. The prevalence of adenomas increases with the patient's age. Having in mind that the risk of malign adenoma transformation is 10 years average, and that small lesions have no clinical potential to turn into cancer, their removal would lead to unnecessary complications and additional costs. CRC risk grows both with the size and the number of adenomas. In patients who refuse polypectomy, we can expect cancer development in average of 5 years $4 \%$ and in 10 years $14 \%$.
\end{abstract}

Case report. We present a patient with a years long history of rectal polyp. She has refused any treatment of polyp removal up so far. Due to stool problems, mostly constipation, occasional bleeding and falling out feeling, she has decided to remove the polyp. The polyp has been detected through colonoscopy and described as very risky for polypectomy due to its suspected malign appearance. We did rectum MR on 1.5T Siemens, so that the patient came with clean lumen into which we applied ultra sound gel with huge $60 \mathrm{ml}$ syringe (no needle) simply and pain free with three fillings (total $180 \mathrm{ml}$ of gel). We have concluded that the polyp was of uneven outline and stretched partially along the inner rectum wall without extra rectal infiltration into mesorectal area. After that, we performed endoscopic polypectomy according to peace meal method resection up to real muscular layer after adrenalin undermining. Pathohistological finding which was done in HE technique showed tubulovillous adenoma.

Conclusions. Rectal MR is a new, very reliable method of contemporary radiological imaging that gives better characterization of polyp tissue and of other tumours. It is currently the best imaging modality enabling very accurate evaluation and topographic ratio of tumour growth within the rectum wall and outside the wall, especially compared to mesorectal fascia. In addition, it is a very comfortable procedure without radiation. The application of ultra sound gel as intra luminal rectal contrast agent can distend the lumen and make an excellent contrast of lumen against the rectum wall and thus can better show polyps and tumours.

Key words: colorectal polyps; colorectal cancer; tubulovillous adenoma; polypectomy; rectum MRI 


\section{Introduction}

Colorectal polyps are frequent and can be found in $10 \%$ of adults, most common in elderly with prevalence of $20 \%$ in age group of 60 . Over $90 \%$ cases of cancer are being developed from benign adenomas. Colorectal cancer (CRC) is a significantly large cause of death right after bronchial cancer in males, and breast cancer in women. Therefore, a standpoint was adopted that the removal of polyps as precursor will prevent the development of colorectal area cancer. ${ }^{1,2}$ Polyps can occur as peduncular or sessile.

Adenomas are grouped in three subtypes based on tubulovillous histological criteria: tubular, tubulovillous and villous. Tubular adenomas are most frequent $-80-86 \%$, tubulovillous are somewhat less frequent - 8$16 \%$, and villous only $5 \%$. Villous adenomas are larger than other adenomas and show a higher level of dysplasia. They can be found mostly in rectum and rectosigmoid area although they can appear anywhere. They are famous for their possibility of malignant transformation., ${ }^{3,4}$ Adenomas malignly alterate in $40 \%$ of cases. Besides, they can bleed, obstruct, invaginate and make torsion. It is believed that the adenoma occurrence is linked both with the abnormal cell proliferation and the apoptosis process. Clinical, histopatological and epidemiological studies enable us to have an insight into adenoma progressing into cancer. Molecular genetic trials describe transit adenoma-cancer through the accumulation of multiplied genetic mutation resulting into the transit from normal adenoma mucosa into dysplasia and then into cancer. Minimal adenoma progression time into CRC is 4 years, and

Received 15 February 2008

Accepted 15 March 2008

Correspondence to: Amela Sofić, MD, Institute of Radiology KCUS, Bolnička 25, 71000 Sarajevo, Bosnia and Herzegovina. Phone/Fax: +387 33444 553; E-mail: amelasofic@yahoo.com median is 10 years from the time of setting diagnosis. ${ }^{5}$

Numerous sources provide an insight into records indicating that CRC that were found during operations are made of one or several synchronic adenomas. The CRC risk grows both with the size and number of adenomas. In patients who refuse polypectomy, we can expect cancer development in average of 5 years $4 \%$, and in 10 years $14 \%$. The frequency of adenoma occurrence in USA indicates that the adenoma prevalence is closely connected to the frequency of CRC occurrence. Regions with law polyps prevalence $-12 \%$ are Costa Rica and Columbia while countries with really high prevalence - $30-40 \%$ are USA, Canada, West Europe, Argentina, New Zealand, Australia. The race is not an insignificant factor for adenoma prevalence, although regional belonging is taken into account as a factor. We can cite example of African Americans in USA who suffer from the disease much more than the blacks in South Africa. A similar example is with the yellow race where Japanese suffer more from the disease than those on Hawaii. In general, the risk of adenoma occurrence does not depend on gender, although some authors suggest insignificant predominance in male population. The prevalence of adenoma increases with the patient's age. In fifties, the prevalence is $30 \%$, in sixties $40-50 \%$, and in seventies $50-65 \%$. Distribution of polyps varies with age. $75 \%$ polyps of $10 \mathrm{~mm}$ and more are located distally. In patients of age 65 and more, $50 \%$ of polyps size $10 \mathrm{~mm}$ and more are located more proximally. ${ }^{6}$

Two thirds of polyps are asimptomatic and have insignificant lab findings. A polyp larger than $1 \mathrm{~cm}$ can show symptoms such as rectal bleedings and abdominal pain. Nonspecific symptoms are diarrhoea, constipation and flatulence. Changes in stool caliber are usually related to large distal polyps. French data from records in Côte- 

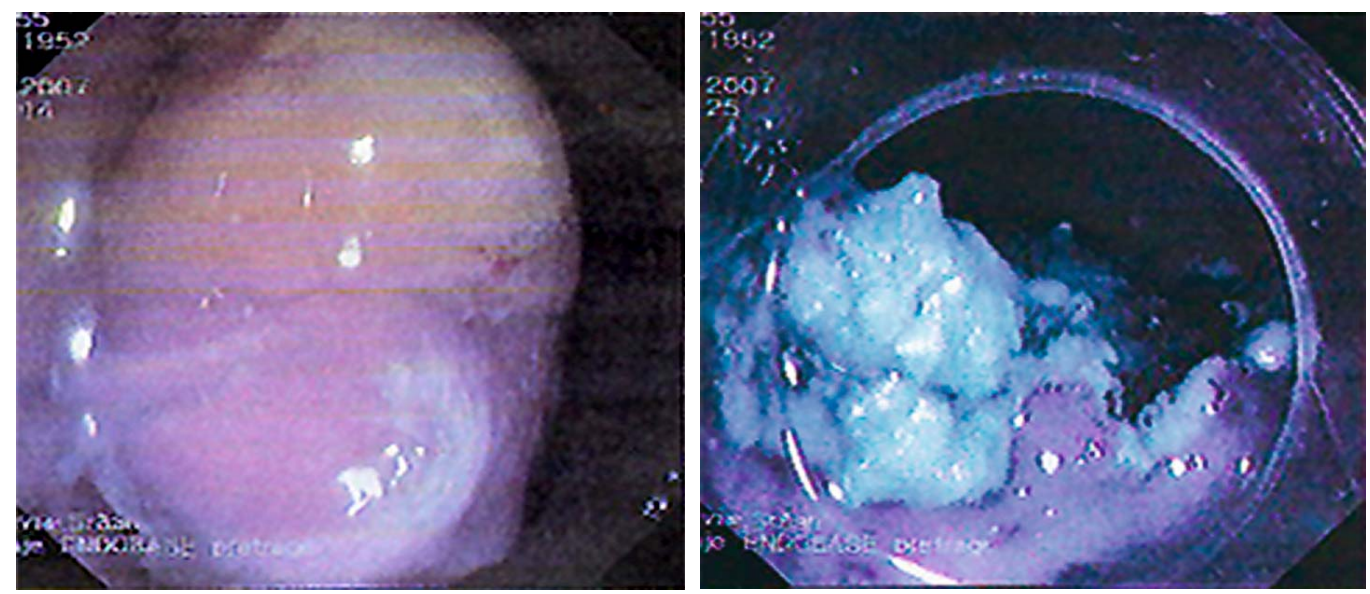

Figure 1. Colonoscopic appearance of tubovillous adenoma.

d'Or indicate that $70 \%$ of polyps detected during colonoscopy are smaller than $1 \mathrm{~cm}$ in diameter, which represents a strategic problem in prevention. In addition, most of these small polyps are not adenomas but mucosa hyperplasia without malign potential. Having in mind that the risk of malign adenoma transformation is 10 years average, and that small lesions have no clinical potential to turn into cancer, their removal would lead to unnecessary complications and additional costs. ${ }^{5}$

Around $40-50 \%$ of all cancers are in rectum. The question is what to do when we detect a polyp through MRI. Target groups are, in any case, polyps larger than $1 \mathrm{~cm}$ which could have a villous and displastic component. The standpoint that all polyps larger than $1 \mathrm{~cm}$ must be removed either endoscopically or surgically is generally accepted. There are no concrete agreements as to polyps smaller than $1 \mathrm{~cm}$. The possibility of malign polyp transformation smaller than $5 \mathrm{~mm}$ is less than $1 \%$, and of $6-9 \mathrm{~mm}$ exactly $1 \%$. Thus, there are opinions that polyps smaller than $5 \mathrm{~mm}$ should be monitored in screening interval from 5-10 years since it is believed that such many years it takes for their malignant degeneration. There are also opposing opinions that any polyp, no matter of size, should be removed. Flat adenomas or non-polypoid adenomas are defined as lesions with flat morphology and are less than $2 \mathrm{~mm}$ of height. There are controversies about the significance of such lesions having in mind their frequency $-8.5-42 \%$. The frequency of malign degeneration is not known. Optical colonoscopy can anticipate these lesions even when using enlargement and chromoscopy. It can be expected that both CT colonographically and MR colonographically anticipate these lesions.

\section{Case report}

Our patient is 55 and has a year long history of rectal polyp. She has refused any treatment of polyp removal up so far. Due to stool problems, mostly constipation, occasional bleeding and falling out feeling, she has decided to remove the polyp. The polyp has been detected through colonoscopy and described as very risky for polypectomy due to its suspected malignant appearance (Figure 1). Colonoscopy operator could not give information about possible malignant alteration, infiltration of rectum wall or penetration into mesorectal tissue. 


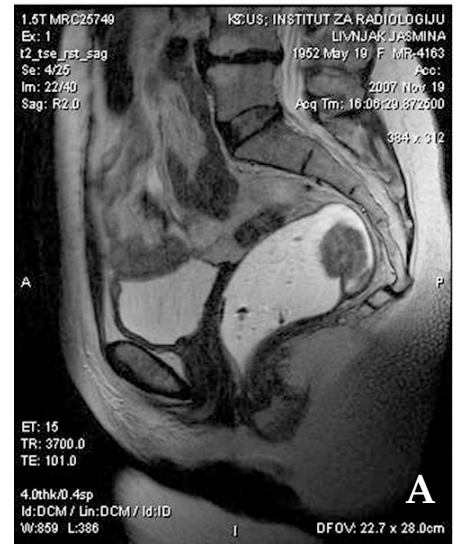

T2 tse sag

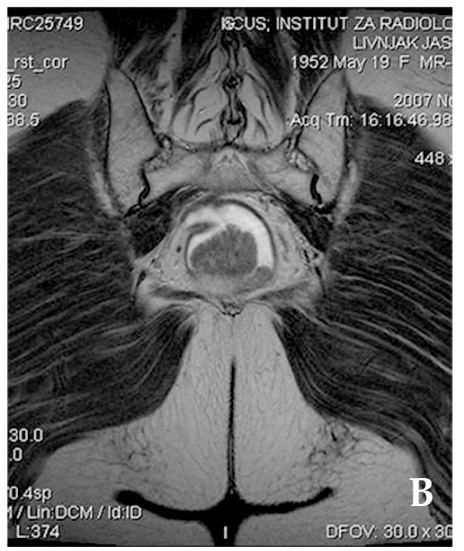

T2 tse cor

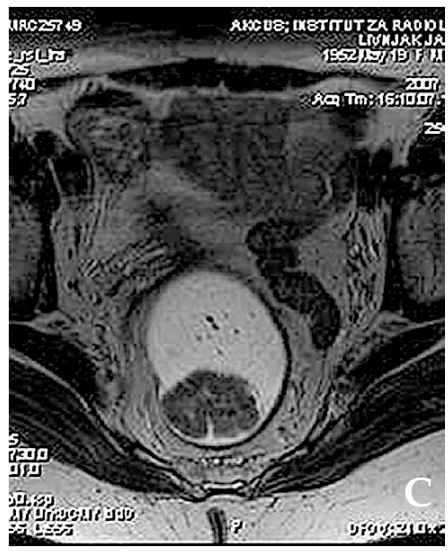

T2 tse tra

Figure 2a,b,c. MR rectum imaging. Lumen of rectum filled with the ultra sound gel appeared as water in T2 in intensive homogeneous hyper signal, and polyp in hypo signal.

We did rectum MRI on 1.5T Siemens, so that the patient came with clean lumen into which we applied ultra sound gel with huge $60 \mathrm{ml}$ syringe (no needle) simply and pain free with three fillings (total $180 \mathrm{ml}$ of gel). We took out the syringe and gel was left in lumen, it did not leak out. The patient felt very comfortable lying on her back. We did rectum MRI following the appropriate protocol and intravenous (IV) application of gadolinium contrast produced by Schering (Magnevista) in the amount of $10 \mathrm{ml}$. We used Body matrix coil placed on pelvis so that the lower edge of coil was below the pubic bone. Coil was attached with a belt, and the patient entered the machine head forward. The protocol has the following sequences -T1fl3d cor fsFOV400 slice thickness 2 mmTR $3.25 \mathrm{~ms}$ PE $1.2 \mathrm{mls}$ voxelsize $1.7 \times 1.6 \times 2 \mathrm{~mm}$. T2 trufi $3 \mathrm{~d}$ cor FOV 450, slth $1 \mathrm{~mm}$ TR 4.09 , TE 1.8 voxelsize $1.6 \times 1.4$ $x$ 1, T2 tsesag FOV 280 slth4mmm TR 3700, TE 101 voxel size $0.7 \times 0.7 \times 4$, Afterwards T2tse tra FOV 210, slth 4 mm TR 3730, Te

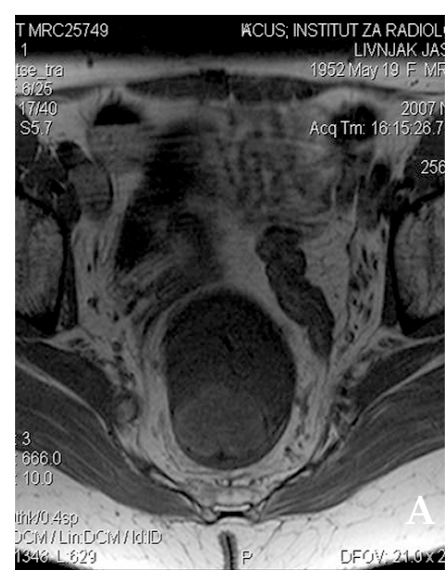

$\mathrm{T} 1$ tse tra

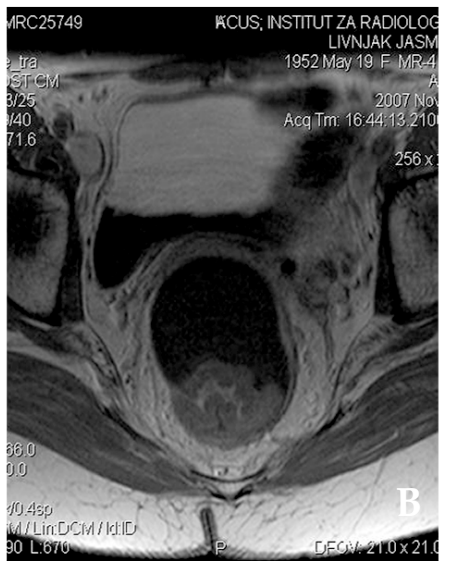

T1 tse tra (post cm magnavist $10 \mathrm{ml}$ )

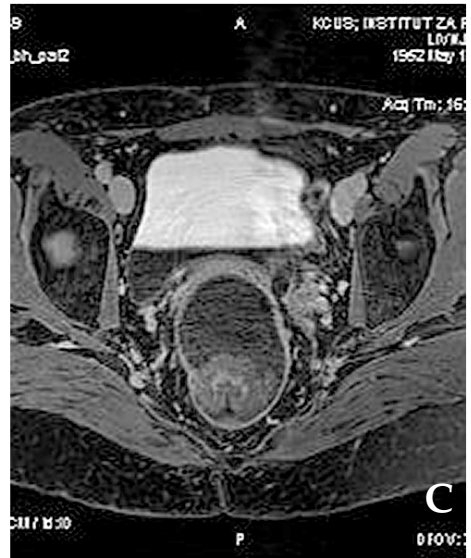

T1 vibe fs tra

Figure 3a,b,c. MR rectum imaging. The polyp itself appeared in T1 in hypo signal very clearly defined against rectum lumen. 


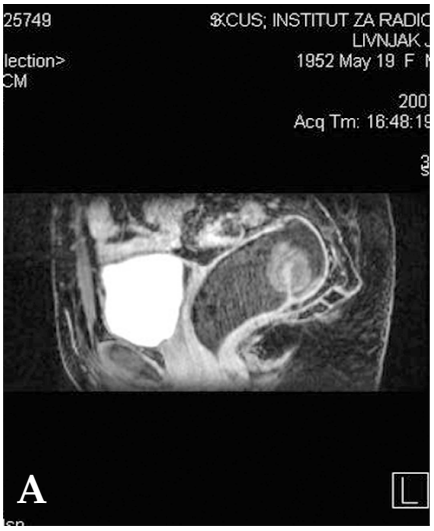

T1 vibe fs MPR post $\mathrm{cm}$

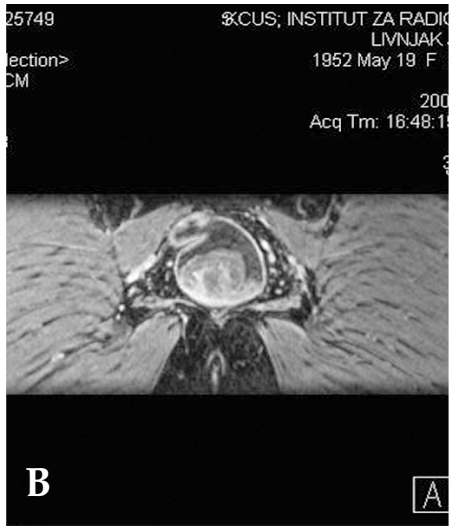

T1 vibe fs MPR post $\mathrm{cm}$

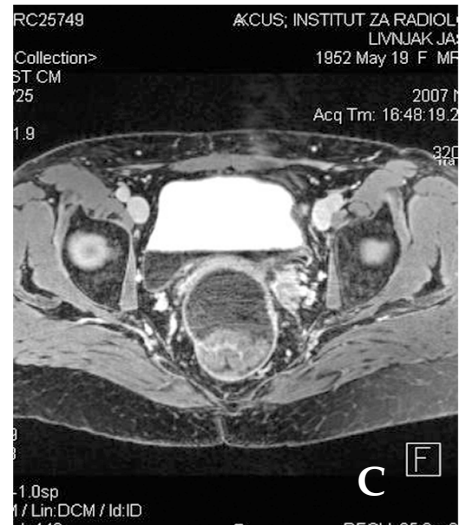

T1 vibe fs MPR post $\mathrm{cm}$

Figure $4 \mathbf{a}, \mathbf{b}, \mathbf{c}$. MR rectum imaging. After IV application of gadolinium, the polyp as well as the rectum wall raised the signal intensity showing a clear polyp characterization.

101 voxelsize $0.8 \times 0.8 \times 4$. T2 cor FOV 300 slth $4 \mathrm{~mm}$, TR 5230 Te 99, voxelsize $0.7 \mathrm{x}$ $0.7 \times 4$. Vibe T1 fs tra FOV 450, TR 4.99, Te 2.61, slth $2.5 \mathrm{~mm}$ voxelsize $2.7 \times 1.8 \times 2.5$ T1 tsetra Fov210, slth4mm, TR 666, TE10, voxelsize $0.8 \times 0.8 \times 4$. We got excellent polyp and rectum lumen images. Lumen of rectum filled with the ultra sound gel appeared as water in T2 in intensive homogeneous hyper signal, and polyp in hypo signal (Figures 2a-2c). The polyp itself appeared in $\mathrm{T} 1$ in hypo signal very clearly defined against rectum lumen (Figures 3a3c). After IV application of gadolinium, the polyp as well as the rectum wall raised the signal intensity showing a clear polyp characterization (Figures $4 a-4 c$ ).

Central part and stalk were of the same larger intensity compared to other parts of the polyp. We have concluded that the polyp was of uneven outline and stretched partially along the inner rectum wall without any extra rectal infiltration into mesorectal area. After that, we performed the endoscopic polypectomy according to peace meal method resection up to real muscular layer after adrenalin undermining (Figure 5). Substance was sent to pathohistological analysis in two containers, one with upper parts of polyp and the other with lower base parts. Pathohistological findings of both substances, which were done in HE technique, showed tubovillous adenomas. Pathohistological diagnose of base parts of substances in the first container was Particulae adenomatis tubullovilosi cum dysplasia gradus gravis focalis colonis. Pathohistological diagnose of the upper part of polyp reads Partticula adenomatis tubullovilosi inflammati cum dysplasia gradus gravis focalis epithelii superfitialis et glandularum adenomatis colonis.

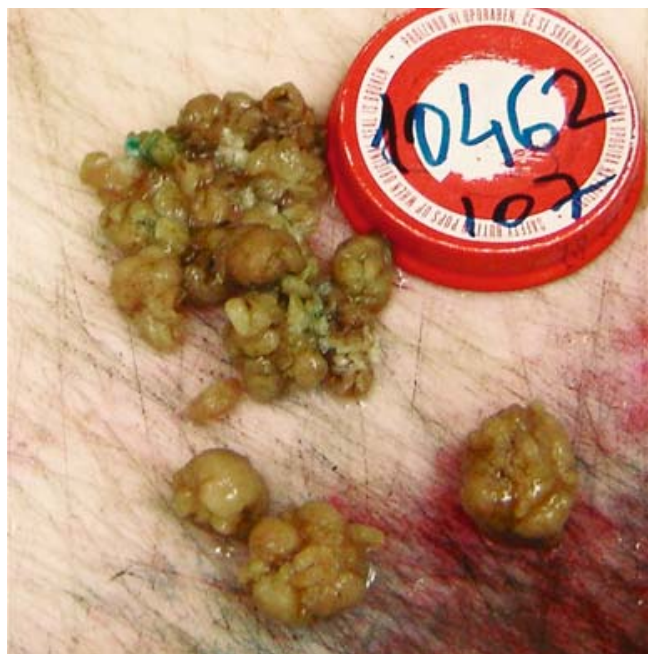

Figure 5. Macroscopic appearance of tubovillous adenoma. 


\section{Discussion}

Irigography and classic colonoscopy have been used to diagnose polyps so far. We have recently started using CT colonography, MR colonography or targeted MR of rectum, as well as endoscopic ultra sound (EUS). The accuracy of pathological lesions detected through EUS is between 69-97\%. It is the oldest and most appropriate widely used imaging technique. Unfortunately, it is not suitable for the evaluation of progressed tumour processes. EUS detects anatomical layers of the rectal wall, but not the relation of tumour and mesorectal fascia. The accuracy of CT colonography in detecting polyps is between $60 \%$ for polyps under $1 \mathrm{~cm}$ and $100 \%$ for those larger than $1 \mathrm{~cm}^{7}$ The accuracy of irigography for polyps is between $40 \%-70 \% .{ }^{8}$ The accuracy of classic colonoscopy for polyps is up to $85 \%{ }^{9}$

It is known that MRI represents imaging modality with the highest contrast between the soft tissues. This is the reason why the MRI is used for rectal cancer staging. The first initial results with MRI were disappointing. The initial results were so poor due to the use of only whole body-coil systems which at first made bad spatial resolution. Once we started using endorectal coil, we have achieved satisfactory results as well as with EUS. ${ }^{10,11}$ However, endorectal coil shows several shortcomings. As in EUS field of view (FOV) is pretty small and enables the evaluation of non-progressed rectum processes but does not enable the depiction of other pelvic anatomic structures. ${ }^{12}$ Besides, the insertion of endorectal coil can be very painful and uncomfortable in progressed pathological processes. Some authors fill rectum with positive or negative enteral contrast agent while some are of opinion that no preparation is necessary. The application of spasmolytic drug or IV administration of gadolinium contrast agent is also the subject to discussion. There are controversies regarding the need to apply IV administration of gadolinium. Many are of opinion that it is unnecessary since the tumour is well visualized in T2 sequences if the rectum is thoroughly distended with water. Wallengren et al. examined the patients using ferristene solution and IV administration of gadodiamide and achieved $100 \%$ sensitivity. Lupo et al. compared the results of pathological process examination without enema and with water enema and proved that the accuracy is higher with water enema -up to $84 \%$. Today, it has also been experimented with MRI of colorectal area without the prior enteral purification and the use of lactulose per os, and water per rectum. In that case, lactulose would mark faeces with hypo intense dark (faecal tagging) while polyps and tumours would remain light -i.e. hyper intense. ${ }^{1}$

Some studies suggest barium ${ }^{13}$ or super paramagnetic iron oxide ${ }^{14}$ as rectal MRI contrast agent. The use of ultra sound gel as endorectal contrast agent is cited in the work of Fletcher and Bharuche. While studying anorectal structures and functions, Berman et al examined the purposefulness of MRI in anorectal dysfunctions including fistulas, abscesses and tumors. ${ }^{15-17}$ Halligan deals with pelvis MRI dynamics. ${ }^{18}$ In future we can expect similar researches with ultra sound gel and filling of not only rectum but maybe even vagina in examinations of gynaecological illnesses.

\section{Conclusions}

Rectal MRI is a new, very reliable method of contemporary radiological imaging that gives better characterization of polyp tissue and of other tumours. It is currently the best imaging modality enabling a very accurate evaluation and topographic ratio of tumour growth and rectum wall and 
outside the wall, especially compared to mesorectal fascia. In addition, it is a very comfortable procedure without radiation. The application of ultra sound gel as intra luminal rectal contrast agent can distend the lumen and make an excellent contrast of lumen against the rectum wall and thus better show polyps and tumours.

\section{References}

1. Ajaj $\mathrm{W}$, Lauenstein $\mathrm{CH}$, Schneemann $\mathrm{H}$, Knehle C, Herborn UC, Goehde CS, et al. Magnetic resonance colonography without bowel cleansing using oral and rectal stool softeners/fecal cracking/-feasibility study. Eur Radiol 2005; 15: 2079-87.

2. Winawer SJ, Zauber AG, Ho MN, O'Brien MJ, Gottlieb LS, Sternberg SS, et al. Prevention of colorectal cancer by colonoscopic polypectomy. The national Polyp Study Workgroup. N Engl J Med 1993; 329: 1977-81.

3. O'Brien MJ, Winawer SJ, Zauber AG, Gottlieb LS, Sternberg SS, Diaz B, et al. The national polyp study: patient and polyp characteristics associated with high grade dysplasia in colorectal adenomas. Gastroenetrology 1990; 98: 371-9.

4. Brkic T, Grgic M. Colorectal Carcinoma. Medicus 2006; 15: 89-97.

5. Blachar A, Sosna J. CT colonography (virtual colonoscopy): technique, indications and performance. Digestion 2007; 76: 34-41.

6. Ramji A. Villous adenoma. 2006; http//www. emedicine.com

7. Roddie M. CT colonography tools advance in clinical use. Diagnostic Imaging Europe 2006; 10: 35-7

8. Steine S, Stordahl A, Oclocer LK, Laeviw C. Doubl-contrast barium enema versus colonoscopy in the diagnosis of neoplastic disorders: aspects of decision-macing in general practice. Fam Pract 1993; 10: 288-91.

9. Ott DJ, Gefand DW, WuWC, Kerr RM. Sensitivity of double-contrast barium enema emphasis on polyp detection. AJR Am J Roentgenol 1980; 135: 327-30.
10. Geenen RW, Hussain SM, Cademartiri F, Poley JW, Siersema PD, Krestin GP. CT and MR colonography: scanning techniques, postprocessing, and emphasis on polyp detection. Radiographics 2004; 24: e18.

11. Chan TW. Kressel HY, Milestone B, Tomachefski J, Schnall M, Rosato E, et al. Rectal carcinoma: staging at MRI imaging with endorectal surface coil. Work in progress. Radiology 1991; 181: 461-7.

12. Goldman S, Arvidsson H, Norming U, Lagerstedt U, Magnusson I, Frisell J. Transrectal ultrasound and computed topography in preoperative staging of lower rectal carcinoma. Gastrintest Radiol 1991; 16: 259-63.

13. Klessen C, Rogalla P, Taupitz M. Local staging of rectal cancer: the current role of MRI. Eur Radiol 2007; 17: 379-89.

14. Panaccione JL, Ros PR, Torres GM, Burton SS. Rectal barium in pelvic MR imaging: initial results. J Magn Reson Imaging 1991; 1: 605-7.

15. Maier AG, Kersting-Sommerhoff B, Reeders JW, Judmaier W, Schima W, Annweiler AA, et al. Staging of rectal cancer by double-contrast MR imaging using the rectally administered super paramagnetic iron oxide contrast agent ferristene and IV gadodiamid injection: results of a multicenter phase II trial. J Magn Reson Imaging 2000; 12: 651-60.

16. Berman L, Israel GM, McCarthy SM, Weinreb JC, Longo WE. Utility of magnetic resonance imaging in anorectal disease. World J Gastroenterol 2007; 13: 3153-8.

17. Fletcher JG, Busse RF, Riederer SJ, Harigh D, Gluecker T, Harper CM, et al. Magnetic resonance imaging of anatomic ad dynamic defects of the pelvic floor in defecatory disorders. Am J Gastroeneterology 2003; 98: 399-411.

18. Halligan S. Dynamic pelvic MRI. Imaging 2001; 13: 458-61. 